\title{
Potential of Martensitic Stainless Steel X5CrNiCuNb 16-4 as Pipe Steel in Corrosive CCS Environment
}

\author{
Anja Pfennig and Axel Kranzmann
}

\begin{abstract}
Pipe steels suitable for carbon capture and storage technology (CCS) require resistance against the corrosive environment of a potential CCS-site (heat, pressure, salinity of the aquifer, $\mathrm{CO}_{2}$-partial pressure). $\mathrm{X} 5 \mathrm{CrNiCuNb16}-4$ has been proven to be sufficient resistant in corrosive environments, but shows rather unusual corrosion behaviour in CCS environment. Therefore differently heat treated coupons of 1.4542 were kept at $T=60{ }^{\circ} \mathrm{C}$ and ambient pressure as well as $p=100$ bar for $700 \mathrm{~h}$ - $8000 \mathrm{~h}$ in an a) water saturated supercritical $\mathrm{CO}_{2}$ and b) $\mathrm{CO}_{2}$-saturated synthetic aquifer environment similar to on-shore CCS-sites in the Northern German Basin. Additionally fatigue tests were performed via push-pull tests with a series of 30 specimens was tested at stress amplitudes between $150 \mathrm{MPa}$ and $500 \mathrm{MPa}$ (sinusoidal dynamic test loads, $R=-1$; resonant frequency $\sim 30 \mathrm{~Hz}$ ). Best corrosion resistance in the liquid phase is achieved via normalizing prior to exposure and hardening+tempering at $670{ }^{\circ} \mathrm{C}$ leads to lowest corrosion rates in the supercritical phase. With no regard to atmosphere discontinuously ellipsoidal surface corrosion regions appear after exposure of $4000 \mathrm{~h}$ and more. The endurance limit of $\mathrm{X5CrNiCuNb16-4}$ measured in air is reduced by more than $50 \%$ when exposed to CCS environment (maximum number of cycles $\left(10 \times 10^{6}\right)$ at a stress amplitude of $\left.150 \mathrm{MPa}\right)$ The scatter range $T N=1: 34$ is disproportionately large contributing to an overall unusual corrosion behaviour
\end{abstract}

Index Terms-Corrosion, CCS, carbon storage, aquifer, heat treatment, fatigue, endurance limit.

\section{INTRODUCTION}

During the compression of emission gasses e.g. from combustion processes of power plants into deep geological layers of a geological on-shore saline aquifer CCS-site (CCS Carbon Capture and Storage [1], [2]), the corrosion of injection pipe steels may become an issue when are compressed [3]-[9]. $\mathrm{CO}_{2}$-corrosion is sensitively dependent on

- alloy composition,

- contamination of alloy and media,

- temperature,

- $\mathrm{CO}_{2}$ partial pressure,

- flow conditions

- protective corrosion scales [5], [6], [10]-[21].

Alloying elements [22] as well as heat treatment (temperature and time of austenitisizing, cooling rate as well

Manuscript received August 30, 2016; revised October 30, 2016.

Anja Pfennig is with HTW University of Applied Sciences Berlin, Wilhelminenhofstraße 75 A, Gebäude C, 12459, Berlin, Germany (e-mail: anja.pfennig@htw-berlin.de).

Axel Kranzmann is with BAM Federal Institute of Materials Research and Testing, Unter den Eichen 87, 12205, Berlin, Germany (e-mail: axel.kranzmann@bam.de). as temperature and time of annealing [23]-[25]) shows significant influence upon the corrosion resistance of steels, e.g. high $\mathrm{Ni}$ - and $\mathrm{Cr}$ contents [26], [27] improve general corrosion resistance as well as retained austenite improves pitting corrosion resistance [26]. Higher austenitizing temperature of martensitic steels [28]-[30] as well as higher annealing temperature of lean duplex stainless steels [22], [23], [28] decrease the pitting potential. Due to reactive grain boundaries in martensitic microstructure C-Mn (carbon) steels in a $\mathrm{H}_{2} \mathrm{~S}$-containing $\mathrm{NaCl}$ solution shows higher corrosion rates than ferritic or ferritic-bainitic microstructures [31].

Corrosion phenomena were also found to be reason for early failure of materials under cyclic load [32]-[34]. Pit formation on stainless steels is enhanced by chemical reactions, local changes of lattice energy within the steel's surface and mechanical load [35], [36]. Higher grain/phase boundary energy where dual or triple points of grain/phase boundaries occur enhances crack initiation and accelerates crack propagation [32], [34]. This local lattice mismatch also initiates pit -, selective - and inter granular corrosion that lead to crack formation [33]. A possible crack initiation model was presented by Han et al. [37] and modified by Pfennig et al. [35], [36] (Fig. 1).

Surface corrosion layers grow slowly and locally corroded samples usually show the same corrosion products as surface layers [15], [17], acting as corrosion catalyser. Generally siderite $\mathrm{FeCO}_{3}$ [3], [38] is formed on steels exposed to $\mathrm{CO}_{2}$-environment (a) due to the low solubility of $\mathrm{FeCO}_{3}$ in water $\left(\mathrm{p}_{\mathrm{Ksp}}=10.54\right.$ at $25^{\circ} \mathrm{C}$ [29], [37]) leading to anodic iron dissolution. The initial formation of transient $\mathrm{Fe}(\mathrm{OH})_{2}$ [6], [30] (grey area in: a) possibly leads to an increase of the local $\mathrm{pH}$ near the hydroxide film. As a consequence an internal and external ferrous carbonate film precipitates, Han et al. [37] (a and b) according to equations 1 to 6 [15], [29]:

$$
\begin{aligned}
\mathrm{CO}_{2}(\mathrm{~g})+\mathrm{H}_{2} \mathrm{O}(\mathrm{l}) & \rightarrow \mathrm{H}^{+}+\mathrm{HCO}_{3}{ }^{-}(\mathrm{aq}) \\
\text { cathodic: } 2 \mathrm{HCO}_{3^{-}}+2 \mathrm{e}^{-} & \rightarrow 2 \mathrm{CO}_{3}{ }^{2-}+\mathrm{H}_{2} \\
\mathrm{Fe} & \rightarrow \mathrm{Fe}^{2+}+2 \mathrm{e}^{-} \\
\mathrm{Fe}^{2+}+\mathrm{CO}_{3}{ }^{2-} & \rightarrow \mathrm{FeCO}_{3} \\
\mathrm{Fe}^{2+}+2 \mathrm{HCO}_{3}^{-} & \rightarrow \mathrm{Fe}\left(\mathrm{HCO}_{3}\right)_{2} \\
\mathrm{Fe}\left(\mathrm{HCO}_{3}\right)_{2} & \rightarrow \mathrm{FeCO}_{3}+\mathrm{CO}_{2}+\mathrm{H}_{2} \mathrm{O}
\end{aligned}
$$

The internal and external corrosion layer grow depending on the various carbon and oxygen partial pressures (b). Local damage of the ferrous hydroxide film (c) due to mechanical and/or chemical effects exposes the highly porous non-protective ferrous carbonate to the geothermal water with lower $\mathrm{pH}$. The ferrous carbonate film begins to dissolve 
and depassivate the steel (d). Local surface degradation is enhanced because oxygen vacancies consolidate and condense at the hydroxide/brine interface and detach the siderite from the hydroxide film in lateral direction in direction of the applied mechanical stress (e). The flowing corrosive media removes the remaining film causing the pit to grow wider, because the same steps will occur from the beginning on the newly exposed surface (f). Simultaneously crack propagation will take place due to the dynamic load and forces at the pit bottom, because the stress concentrations and plastic deformation lead to the production of slip bands [26] highly susceptible to the corrosion explained. The crack flanks are immediately wetted repeating the corrosion steps within the crack itself.

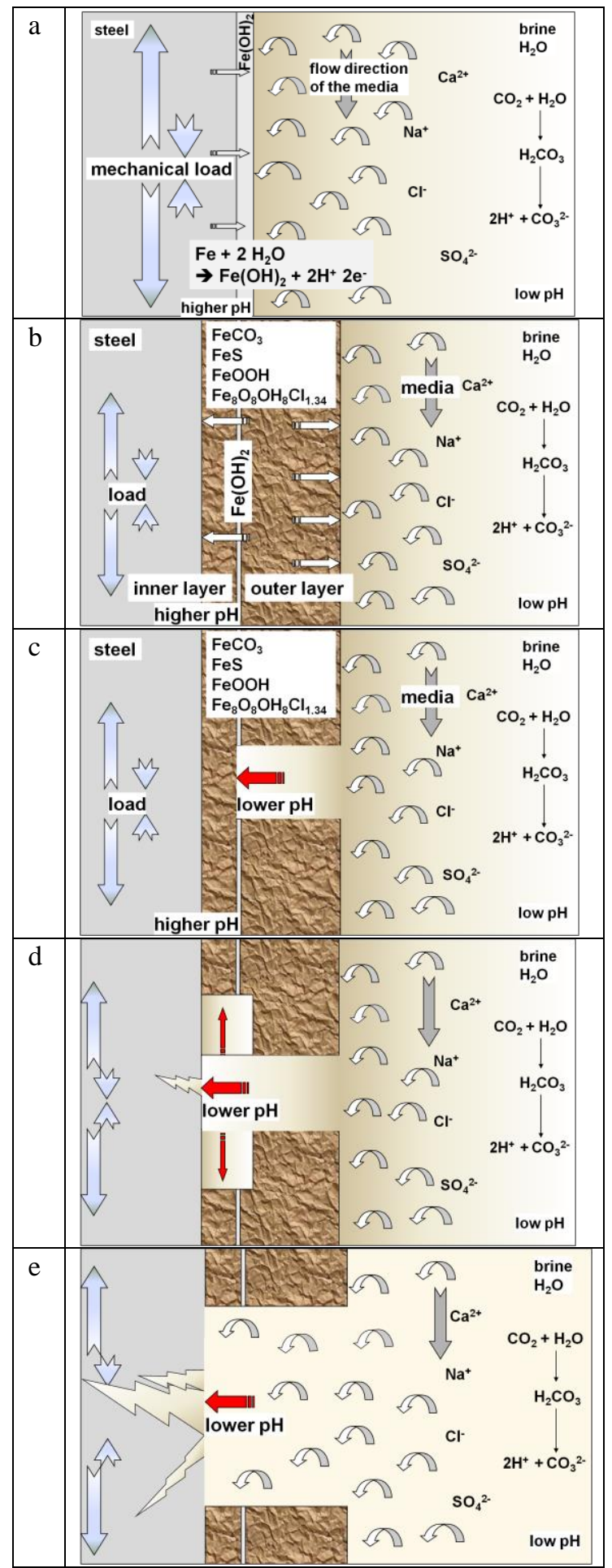

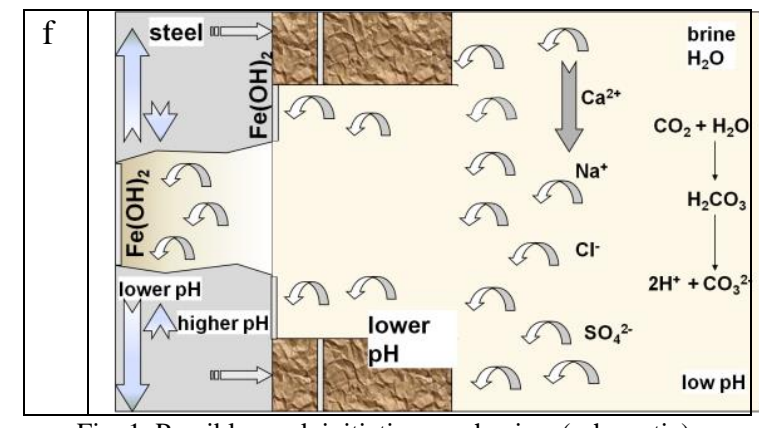

Fig. 1. Possible crack initiation mechanism (schematic).

\section{EXPERIMENTAL PROCEDURE}

\section{A. Material}

Static corrosion tests as well as corrosion fatigue tests were carried out using heat treated samples of martensitic AISI 630 (X5CrNiCuNb16-4, 1.4542 (Table I) and (Table II).

TABLE I: CHEMICAL COMPOSITION OF 1.4542 (X5CRNICUNB16-4, AISI 630), NO CO DETECTED

\begin{tabular}{|c|c|c|c|c|c|c|}
\hline Elements & C & $\mathbf{S i}$ & Mn & $\mathbf{P}$ & $\mathbf{S}$ & $\mathrm{Cr}$ \\
\hline & $\leq$ & $\leq$ & $\leq$ & $\leq 0.04$ & $\leq 0.015$ & $15.0-$ \\
\hline standard $^{\mathrm{a}}$ & 0.07 & 0.70 & 1.50 & & & 17.0 \\
\hline analysed $^{\mathrm{b}}$ & 0.03 & 0.42 & 0.68 & 0.018 & 0.002 & 15.75 \\
\hline Elements & Mo & $\mathbf{N i}$ & \multicolumn{2}{|c|}{$\mathrm{Cu}$} & $\mathbf{N b}$ & $\mathrm{Fe}$ \\
\hline $\begin{array}{l}\text { acc } \\
\text { standard }^{\text {a }}\end{array}$ & $\begin{array}{l}\leq \\
0.60\end{array}$ & $\begin{array}{l}3.00- \\
5.00\end{array}$ & \multicolumn{2}{|c|}{$3.00-5.00$} & $\begin{array}{l}0.20- \\
0.45\end{array}$ & rest \\
\hline analysed $^{\mathrm{b}}$ & 0.11 & 4.54 & \multicolumn{2}{|c|}{3.00} & 0.242 & 75.00 \\
\hline
\end{tabular}

TABLE II: HEAT TREATMENT PROTOCOL FOR X5CRNICUNB 16-4 heat treatment temperature time cooling ${ }^{\circ} \mathrm{C} /{ }^{\circ} \mathrm{C}$ min medium

\begin{tabular}{lccc} 
normalizing & 850 & 30 & oil \\
\hline hardening & 1040 & 30 & oil \\
\hline $\begin{array}{l}\text { hardening }+ \\
\text { tempering } 1,600^{\circ} \mathrm{C}\end{array}$ & $1040 / 550$ & 30 & oil \\
$\begin{array}{l}\text { hardening }+ \\
\text { tempering } 2,670^{\circ} \mathrm{C}\end{array}$ & $1040 / 650$ & 30 & oil \\
$\begin{array}{l}\text { hardening }+ \\
\text { tempering } 3,700^{\circ} \mathrm{C}\end{array}$ & $1040 / 755$ & 30 & oil
\end{tabular}

To simulate in-situ geothermal condition the geothermal quifer water (as known to be similar to the Stuttgart Aquifer [39]: $\mathrm{Ca}^{2+}: 1760 \mathrm{mg} / \mathrm{L}, \mathrm{K}^{2+}: 430 \mathrm{mg} / \mathrm{L}, \mathrm{Mg}^{2+}: 1270 \mathrm{mg} / \mathrm{L}$, $\mathrm{Na}^{2+}: 90,100 \mathrm{mg} / \mathrm{L}, \mathrm{Cl}^{-}: 143,300 \mathrm{mg} / \mathrm{L}, \mathrm{SO}_{4}{ }^{2-}: 3600 \mathrm{mg} / \mathrm{L}$, $\mathrm{HCO}_{3}^{-}: 40 \mathrm{mg} / \mathrm{L}$ ) was synthesized in a strictly orderly way to avoid precipitation of salts and carbonates.

\section{B. Static Experiments}

Laboratory scale exposure tests in $\mathrm{CO}_{2}$-saturated aquifer brine and water saturated $\mathrm{CO}_{2}$ were carried using coupons of the steel quality $\mathrm{X} 5 \mathrm{CrNiCuNb} 16-4$ (1.4542) may be used as injection pipe using samples made of thermally treated specimen of steels with $8 \mathrm{~mm}$ thickness, $20 \mathrm{~mm}$ width, 50 mm length. Heat treatment to gain martensitic microstructure with sufficient hardness and toughness prior to exposure was done following commonly used protocols according to Table II:

A hole of $3.9 \mathrm{~mm}$ diameter was used for sample positioning. Samples of each base metal were positioned 
within the vapour phase and within the liquid phase. Flow control (3 NL/h) of the technical $\mathrm{CO}_{2}$ (purity 99,995 vol.-\%)) into the brine at ambient pressure was done by a capillary meter GDX600_man by QCAL Messtechnik GmbH, Munic. The exposure of the samples between $700 \mathrm{~h}$ to $8000 \mathrm{~h}$ was disposed in reaction vessels according to the conditions at the geological site at $60{ }^{\circ} \mathrm{C}$ at ambient pressure - each material in a separated reaction vessel [15], [40] and at 100 bar [41], [42] (Fig. 2).

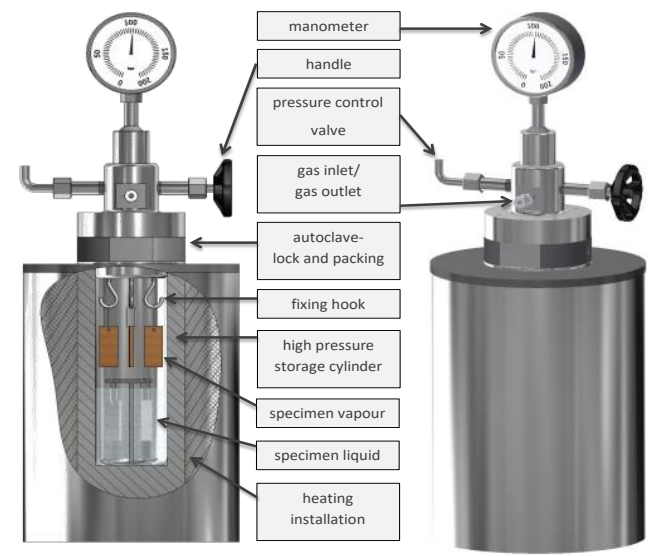

Fig. 2. Reaction vessels and experimental set up.

Before corrosion tests the surfaces of the steels were activated by grinding with SiC-Paper down to $120 \mu \mathrm{m}$ under water. After the corrosion tests, the samples were cut partly for scale analysis with the corrosion layer and prepared partly for kinetic analysis after the scale was etched. Descaling of the samples was performed by exposure to $37 \% \mathrm{HCl}$. Then parts of the samples were embedded in a cold resin (Epoxicure, Buehler), cut and polished first with SiC-Paper from $180 \mu \mathrm{m}$ to $1200 \mu \mathrm{m}$ under water and then finished with diamond paste $6 \mu \mathrm{m}$ and $1 \mu \mathrm{m}$.

\section{Dynamic Experiments}

An appropriate system for fatigue testing at temperatures existing in deep geological layers (in-situ conditions) was set up, to assess materials of components loaded cyclically and exposed constantly to the highly corrosive hot thermal water at $60{ }^{\circ} \mathrm{C}$ and ca. $20 \%$ salinity of the geothermal water and fluid properties differing strongly [39]. Fatigue tests were carried out using samples of martensitic AISI 630 (X5CrNiCuNb16-4, 1.4542, tensile strength in air: $1078 \mathrm{MPa}$ ) (Table I). The surfaces were activated via machining to $\mathrm{Rz}=4$.

The objective was to simulate in-situ conditions (temperature $60{ }^{\circ} \mathrm{C}$, corrosive environment) of a material exposed to dynamic mechanical stress and corrosive gassaturated saline aquifer environment. The corrosion chamber is fixed directly onto the sample leaving the resonant testing machine unaffected (Fig. 3). During mechanical stress-strain tests a magnetically driven gear pump constantly pumps the corrosive media from the reservoir to the corrosion- and temperature-resistant corrosion chamber. The specimen is during the complete test surrounded of the corrosions medium. Heating is realized by a heating element which is placed at the reservoir. The ratio of sample surface to volume of the corrosive media after DIN 50905 Part $1\left(10 \mathrm{ml} / \mathrm{cm}^{2}\right)$ is greater than required. The connecting of the chamber onto the specimen via clamping collar creates a force-fit process ensuring enough force to the corrosion chamber at high frequencies to keep it firmly on the test specimen. The corrosion chamber is sealed by O-rings made of Viton in the area of restraint. In order not to impede the change in length of the sample during the experiment, a membrane is applied to the corrosion chamber as a motion-compensating element. [41], [42].

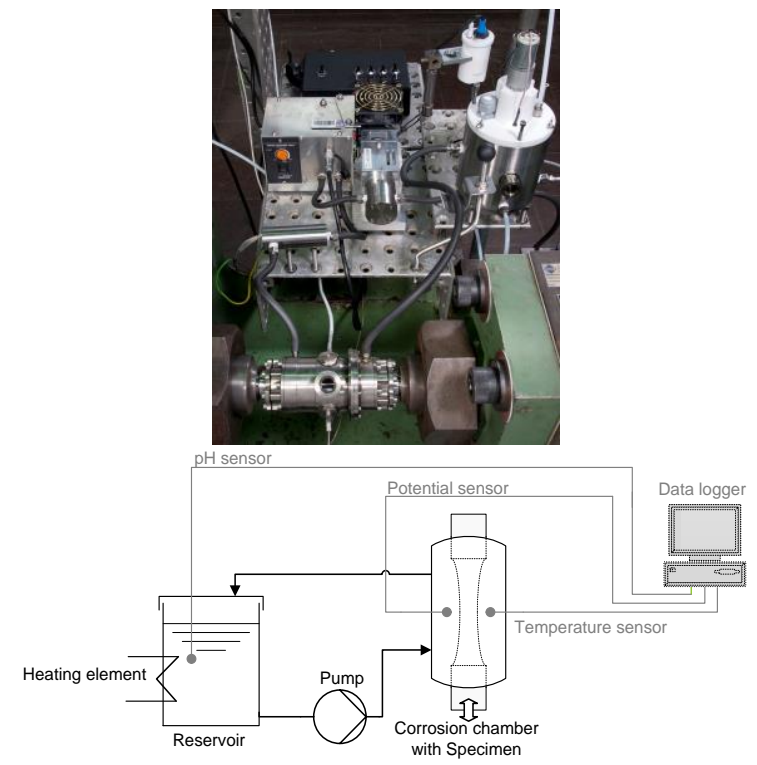

Fig. 3. Schematic set-up of operating corrosion chamber for in-situ corrosion fatigue testing [15], [40].

Electrochemical data were collected in the corrosion chamber during the mechanical tests along with temperature, $\mathrm{pH}$ and electrochemical potential. For measurement of the electrochemical potential a shock resistant silver-silver chloride electrode was fixed in a Teflon channel. To simulate non-static operation a resonant testing machine has been used at $30-40 \mathrm{~Hz}$ where samples of both steels were tested in stress-strain mode under CCS aquifer environment. In addition technical $\mathrm{CO}_{2}$ was introduced into the closed system at a rate close to $9 \mathrm{~L} / \mathrm{h}$ to keep stable environmental conditions.

The corrosion fatigue strength of stainless steel with $16 \%$ chromium (X5CrNiCuNb16-4, 1.4542, hardened and tempered with martensitic microstructure) is examined in dynamic stress-strain tests in $\mathrm{CO}_{2}$-saturated aquifer (Stuttgart Aquifer [40]) at $60^{\circ} \mathrm{C}$. Therefore a resonant testing machine (sinusoidal dynamic test loads, $\mathrm{R}=-1$; resonant frequency $30 \mathrm{~Hz}$ ) has been used. In addition technical $\mathrm{CO}_{2}$ was introduced into the closed corrosion chamber system at a rate close to $9 \mathrm{~L} / \mathrm{h}$ to keep stable environmental conditions. In each test series 30 specimens were tested. X5CrNiCuNb16-4 was tested between $150 \mathrm{MPa}$ and $500 \mathrm{MPa}$. Due to the rather heterogeneous fine machined surfaces (surface roughness $\mathrm{Rz}=4$ ) the specimens are comparable with prefabricated parts.

\section{Analysis}

Different light optical and electron microscopy techniques were performed on specimens to investigate the layer structures and morphology of the samples. X-ray diffraction was carried out in a URD-6 (Seifert-FPM) with 
CoK $\alpha$-radiation with an automatic slit adjustment, step $0.03^{\circ}$ and count $5 \mathrm{sec}$. Phase analysis was performed by matching peak positions automatically with PDF-2 (2005) powder patterns. Mainly structures that were likely to precipitate from the steels were chosen of the ICSD and refined to fit the raw-data-files using POWDERCELL 2.4 [43] and AUTOQUAN $®$ by Seifert FPM. To characterise the pitting corrosion, 3-D-images were realized by the double optical system Microprof TTV by FRT. Kinetics of the corrosion were determined by the corrosion rates which were calculated via mass change of the samples before and after corrosion testing according to DIN 50905 part 1-4 and using the semi-automatic analyzing program Analysis Docu ax-4 by Aquinto.

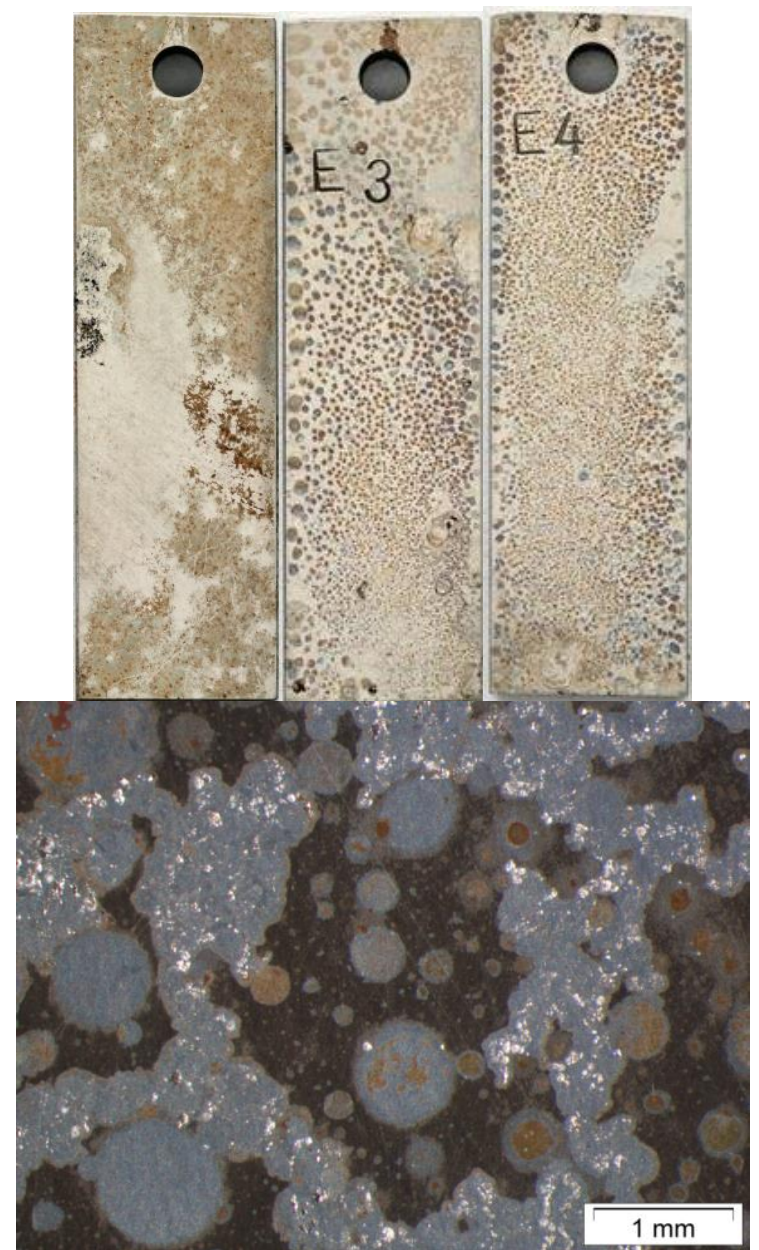

Fig. 4. Sample surfaces of $\mathrm{X} 5 \mathrm{CrNiCuNb} 16-4$ hardened and tempered at $670{ }^{\circ} \mathrm{C}(\mathrm{E} 3)$ and $700{ }^{\circ} \mathrm{C}(\mathrm{E} 4)$ after $4000 \mathrm{~h}$ of exposure in water saturated supercritical $\mathrm{CO}_{2}$ (upper left and middle) and $\mathrm{CO}_{2}$-saturated brine (upper right).

\section{RESUlTS AND DisCUSSION}

$\mathrm{X} 5 \mathrm{CrNiCuNb} 16-4$ precipitates surface corrosion layers and pits when during CCS injection intermissions and reduced pressure in the injection pipe occur where the water level may rise within the pipe although in general the $\mathrm{CO}_{2}$ is injected in its supercritical phase. This three phase boundary leads to an atmosphere, where surface corrosion results in a discontinuous layer structure described as "leopard" structure. This unusual corrosion formation is present in supercritical water saturated $\mathrm{CO}_{2}$ even after short exposure times (700 h) (Fig. 4) and in $\mathrm{CO}_{2}$-saturated brine after $4000 \mathrm{~h}$ of exposure
[42], [44]. Ellipsoidal regions of the sample surfaces are corroded visually while surrounding regions are protected by a passivating layer.

\section{A. Kinetics of Static Corrosion Experiments}

Samples exposed to water saturated supercritical $\mathrm{CO}_{2}$ and $\mathrm{CO}_{2}$-saturated brine do not reveal a distinct dependence on the heat treatment prior to exposure showing the same trends during the entire exposure time (Fig. 5). Maximum corrosion rate in the liquid phase is approximately $0.014 \mathrm{~mm} /$ year, after $8000 \mathrm{~h}$ and approximately $0.003 \mathrm{~mm} /$ year in the supercritical phase.

Corrosion rates obtained in supercritical $\mathrm{CO}_{2}$ do not change as a function of time. But, long exposure times in $\mathrm{CO}_{2}$-saturated brine lead to increasing surface corrosion rates after $4000 \mathrm{~h}$ due to a possible break-down of the initial passivating layer formed after $1000 \mathrm{~h}$ of exposure. This may be due to increasing carbide precipitation depleting the metal matrix of chromium and therefore prohibiting further surface passivation.
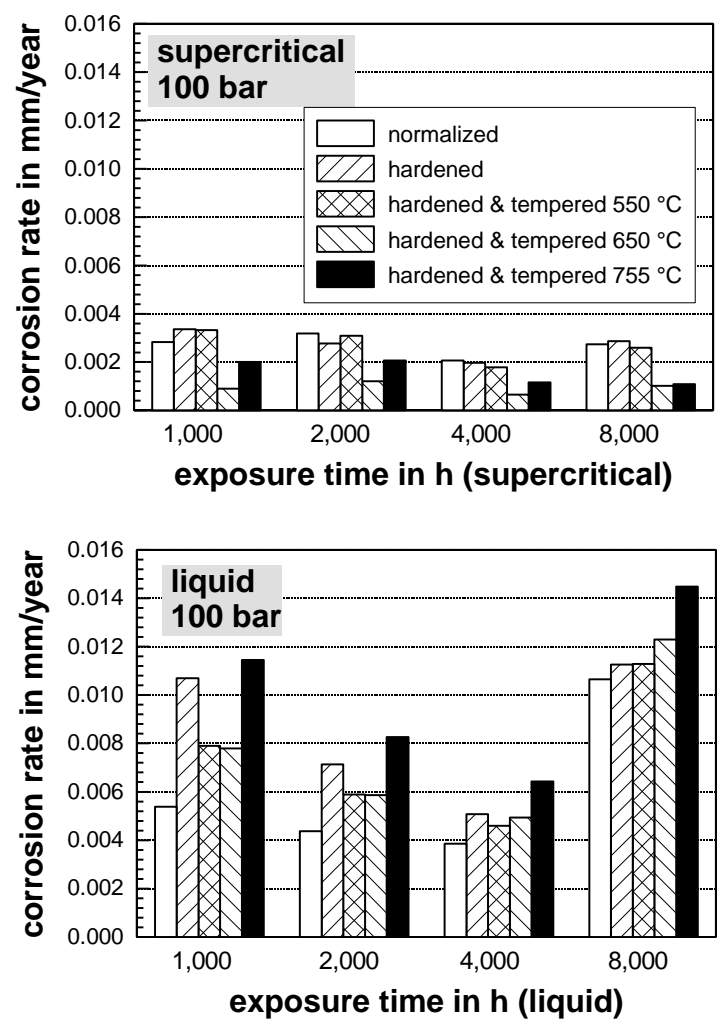

Fig. 5. Influence of heat treatment on the corrosion rate of 1.4542 in water saturated supercritical $\mathrm{CO} 2$ (top) and $\mathrm{CO} 2$ saturated saline aquifer water (bottom [42], [44]) at $60^{\circ} \mathrm{C}$ and 100 bar.

Due to passivation $\mathrm{X} 5 \mathrm{CrNiCuNb} 16-4$ shows very low corrosion rates in water saturated supercritical $\mathrm{CO}_{2}$ depending either on the lack of electrolytes [42] or more possible on the cathodic reaction described in equation (1) leading to a higher $\mathrm{H}_{2} \mathrm{CO}_{3}$ concentration and therefore more acidic and reactive environment as in the $\mathrm{CO}_{2}$ saturated liquid phase [7], [26]. In $\mathrm{CO}_{2}$-containing water carbonic acid is formed due to the low $\mathrm{pH}$ and because the solubility of iron carbonate $\mathrm{FeCO}_{3}$ is low [29] siderite forms. In general, the leopard shaped corrosion layer reveals siderite $\mathrm{FeCO}_{3}$ and goethite a-FeOOH as precipitation phases.

Two explanations are possible for the "leopard shape":

1) Carbides are more susceptible to corrosion initiation [27], 
[42] and therefore the passivation of the steel surface is locally destroyed where carbides precipitated.

2) In water saturated supercritical $\mathrm{CO}_{2}$ at 100 bar and $60{ }^{\circ} \mathrm{C}$ the decreasing water solubility in the supercritical carbon dioxide [26] leads to wetting of the metal surface via very thin and small water droplets. Because time was too short to precipitate pits the typical "leopard" shaped corrosion layer is formed indicating the initial droplets on the surface [42]. Areas of former droplets consolidate resulting in small pits surrounding the former droplet (Fig 4) containing sulphates $\left(\mathrm{FeSO}_{4}\right)$ in the outer areas whereas the center shows hematite $\left(\mathrm{Fe}_{2} \mathrm{O}_{3}\right)$ (Fig. 6).

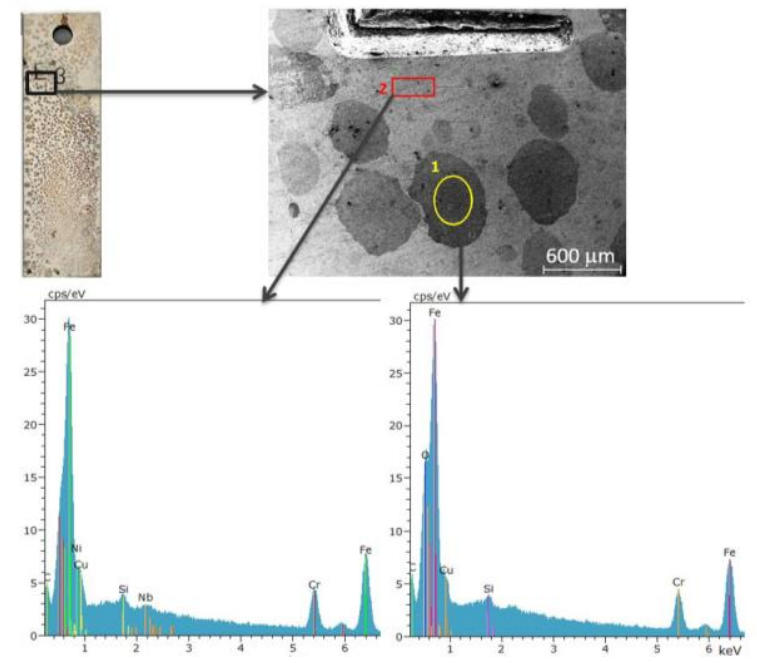

Fig. 6. SEM micrographs and element distribution of the ellipsoidal corrosion layer formed on 1.4542 hardened and tempered at $670{ }^{\circ} \mathrm{C}$ prior to exposure after 8000 hours of exposure at $60{ }^{\circ} \mathrm{C}$ and 100 bar to water saturated supercritical $\mathrm{CO}_{2}$.

The influence on heat treatment prior to exposure has been widely described [11], [22], [28], [29]. Under supercritical $\mathrm{CO}_{2}$ conditions a martensitic microstructure of hardened and tempered 1.4542 at low temperatures $\left(650{ }^{\circ} \mathrm{C}\right)(<0.001$ $\mathrm{mm} /$ year $)$ and under saline water normalized microstructure (ca. $0.004 \mathrm{~mm} /$ year) offer best corrosion resistance regarding surface corrosion (Fig. 5) [42]. Independent of the heat treatment $\mathrm{X} 5 \mathrm{CrNiCuNb} 16-4$ developed a rather high number of pits per $\mathrm{m}^{2}$ in both atmospheres, water saturated supercritical $\mathrm{CO}_{2}$ and $\mathrm{CO}_{2}$ saturated aquifer water (Fig. 7). The number of pits precipitated in the supercritical phase is approximately ten times higher than in the liquid phase. Heat treatment hardening and tempering that showed highest surface corrosion resistance reveals now the greatest number of pits (Fig. 7, top). Pit depths measured after exposure at 100 bar and $60^{\circ} \mathrm{C}$ are about $10-250 \mu \mathrm{m}$.

\section{B. Corrosion Fatigue Behaviour}

The unusual corrosion phenomena of $\mathrm{X} 5 \mathrm{CrNiCuNb} 16-4$ are accompanied by an also unusual corrosion fatigue behavior described by Pfennig et al. [41], [42]. The $\mathrm{S}-\mathrm{N}$-curve did not show typical fatigue strength (Fig. 8). The large scatter range $\mathrm{TN}=1: 34$, the possibility of an influence of three different charges of aquifer water [45] and the very small coefficient of correlation $r^{2}=0.33$ indicate a non-linear relationship of the considered variables giving only a $24 \%$ chance of linear relationship. The corrosion fatigue strength of $\mathrm{X} 5 \mathrm{CrNiCuNb} 16-4$ is $60 \%$ below the endurance limit measured in air (620 MPa). Maximum number of cycles $\left(10 \times 10^{7}\right)$ was reached at a stress amplitude of $150 \mathrm{MPa}$. The decrease of the fatigue limit line with increasing number of cycles (Wöhler-exponent of $\mathrm{k}=3.59$ ) is much larger in corrosive environment than in air [41].
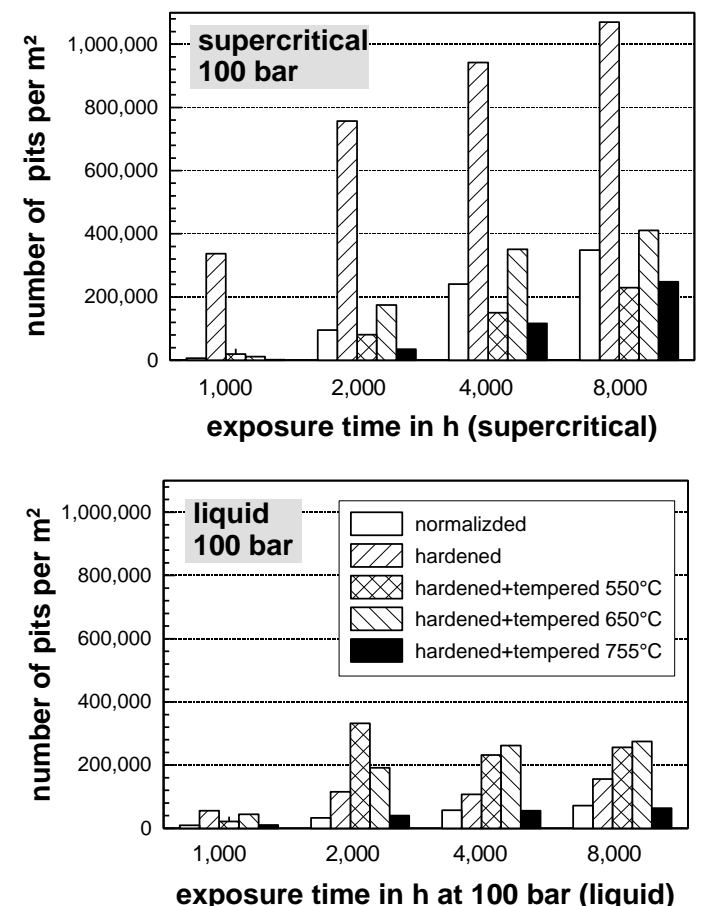

Fig. 7. Influence of heat treatment on the local corrosion of 1.4542 in water saturated supercritical $\mathrm{CO}_{2}$ (top) and $\mathrm{CO}_{2}$ saturated saline aquifer water (bottom [42], [44]) at $60^{\circ} \mathrm{C}$ and 100 bar.

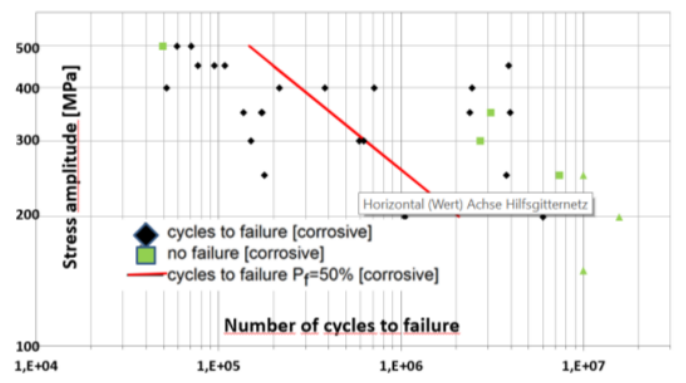

Fig. 8. S-N-curve and sample of 1.4542 exposed to flowing saline aquifer [40] and $\mathrm{CO} 2$ at $60{ }^{\circ} \mathrm{C}$ [41], [45].

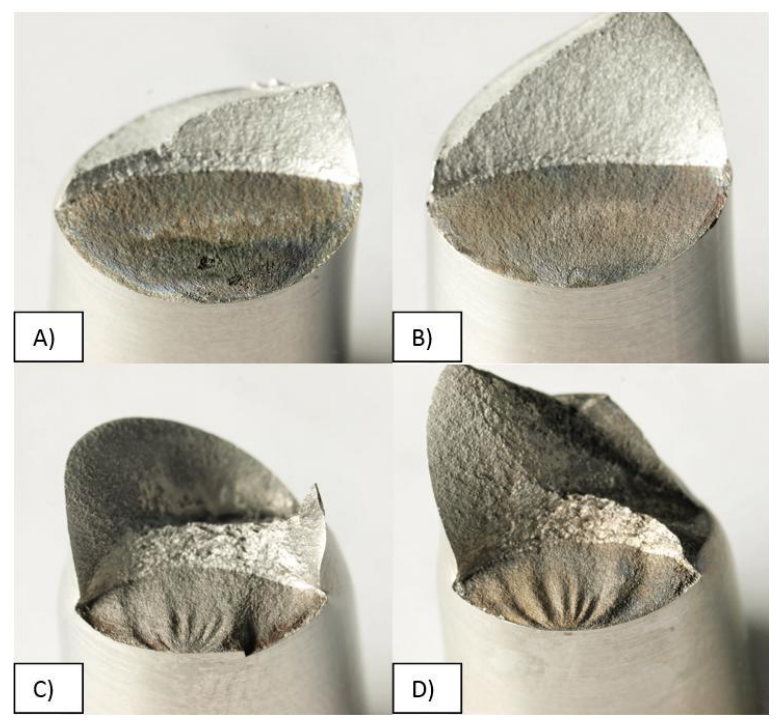

Fig. 9. Crack surfaces after fatigue failure. Samples reveal impurities with no influence on endurance limit. 


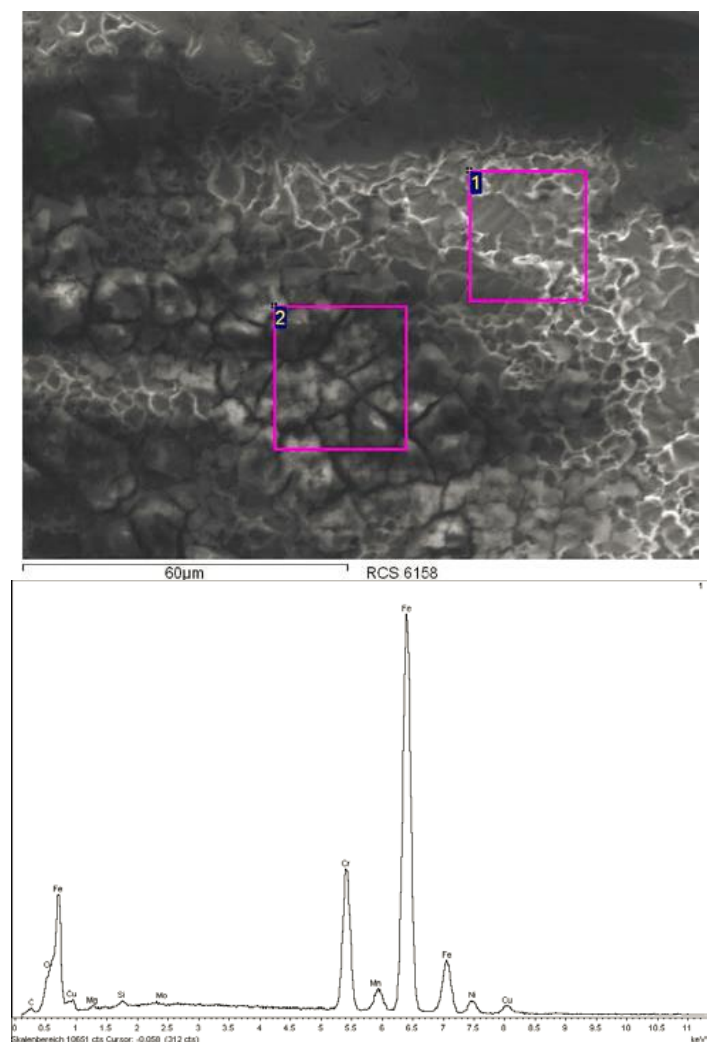

Fig. 10. Surface image (left) of corrosion layer on crack flank and main elements indicating $\mathrm{Al}$ as impurity (right). Element distribution revealing contaminants of the samples.

Local corrosion is enhanced within the microstructure as a result of chlorides [46] and increased dislocation number, grain boundaries, boundaries of precipitation phases e.g. carbides leading to local lattice mismatch resulting in higher local boundary energy [47]. Multiple cracks found throughout the entire sample area of $\mathrm{X} 5 \mathrm{CrNiCuNb} 16-4$ initiated from pits are responsible for early failure. Impurities were found on various surfaces with no significant correlation to the endurance limit (Fig. 9). Surfaces revealed corrosion layers mainly composed of iron carbonate (siderite, $\left.\mathrm{FeCO}_{3}\right)$ and iron hydroxide $\left(\mathrm{Fe}(\mathrm{OH})_{2}\right)$ (Fig. 10). Both, the presence and the thickness of the corrosion layer could not be related to early failure. The number of striations indicating the opening and closing of the initial crack during cyclic load was also not a matter of early or late failure.

After hardening and annealing the microstructure of $\mathrm{X} 5 \mathrm{CrNiCuNb} 16-4$ reveals the typical needle-structure of martensite with embedded $\delta$-ferrite. Samples with short number of cycles to failure contained $\mathrm{Al}$ within the corrosion layer (Fig. 10) and revealed non-metallic inclusions that were ordered discontinuously lamellar within the alloy. It may be assumed that, impurities such as $\mathrm{Al}$ present in the base material may consolidate during cyclic loading within corrosive environment and then lead to unpredictable early failure.

\section{CONCLUSION}

Corrosion rates, local corrosion accompanied with crack initiation are decisive when deciding if the steels are suitable for CCS application. Steels will be unsuitable for its use in pressure vessel applications if the corrosion rate exceeds
$0,1 \mathrm{~mm} /$ year. Neither aquifer water, microstructure of $\mathrm{X} 5 \mathrm{CrNiCuNb16-4}$ nor mechanical properties such as hardness or distinct crack propagation were proved to be of influence on mechanical properties. Crack formation is correlated with pit corrosion phenomena resulting in inter crystalline corrosion. It may also be possible that these impurities lead to local corrosion phenomena, but again failure is not necessary a consequence of local corrosion. Therefore $\mathrm{Al}$ is the only significant evidence for lower endurance limits. However, this still does not fully explain the unusual corrosion and corrosion fatigue behavior of the metal. Reliable corrosion rates and lifetime predictions regarding pit corrosion and corrosion fatigue for $\mathrm{X} 5 \mathrm{CrNiCuNb16}-4$ in CCS technology are not possible. A high sensitivity on a homogeneous microstructure upon the corrosion and corrosion fatigue behaviour of $\mathrm{X} 5 \mathrm{CrNiCuNb} 16-4$ needs to be taken into account when regarding this steel as pipe steel during injection of $\mathrm{CO}_{2}$ into saline aquifers. The following findings may be summarized:

- Surface Corrosion rates are lower in supercritical $\mathrm{CO}_{2}$, but pit corrosion resistance is better in $\mathrm{CO}_{2}$ saturated brine.

- "Leopard structured" surface corrosion is related to chemical decomposition, water and $\mathrm{CO}_{2}$ partial pressure, presence of electrolyte, $\mathrm{pH}$, and early pit formation

- $\mathrm{FeCO}_{3}$ and $\mathrm{FeOOH}$ are corrosion products under static and dynamic corrosion tests

- No correlation could be found between the inclusions and early rupture although specimens with inclusions at the fracture surface and its cross section endured lower number of cycles.

- Al was analyzed in specimens with low number of cycles and may be cause for early rupture during corrosion fatigue tests.

\section{ACKNOWLEDGMENT}

This work was supported by the FNK (Fachkonferenz für wissenschaftliche Nachwuchskräfte) of the Applied University of Berlin, HTW and by IMPACT (EU-Project EFRE 20072013 2/21).

\section{REFERENCES}

[1] D. C. Thomas, "Carbon dioxide capture for storage in deep geologic formations - Results from $\mathrm{CO}_{2}$ capture project," Capture and Separation of Carbon Dioxide form Combustion Sources, 2005, vol. 1.

[2] M. Broek, R. Hoefnagels, E. Rubin, W. Turkenburg, and A. Faaij, "Effects of technological learning on future cost and performance of power plants with $\mathrm{CO}_{2}$ capture, in projects costs of generating electricity," Progress in Energy and Combustion Science, pp. 177-187, 2011.

[3] S. Nešić, "Key issues related to modelling of internal corrosion of oil and gas pipelines - A review," Corrosion Science, vol. 49, pp. 4308-4338, 2007.

[4] S. Hurter, "Impact of mutual solubility of $\mathrm{H}_{2} \mathrm{O}$ and $\mathrm{CO}_{2}$ on injection operations for geological storage of $\mathrm{CO}_{2}$," in Proc. International Conference of the Properties of Water and Steem ICPWS, Berlin, September 8-11.

[5] L. Zhang, J. Yang, J. S. Sun, and M. Lu, "Effect of pressure on wet $\mathrm{H} 2 \mathrm{~S} / \mathrm{CO} 2$ corrosion of pipeline steel, no. 09565," in Proc. NACE Corrosion 2008 Conference and Expo, New Orleans, Louisiana, USA, March 16-20, 2008.

[6] L. J. Mu and W. Z. Zhao, "Investigation on carbon dioxide corrosion behaviors of $13 \mathrm{Cr}$ stainless steel in simulated strum water," Corrosion Science, pp. 1-24, 2009. 
[7] M. Seiersten, "Material selection for separation, transportation and disposal of CO2," NACE Corrosion, 2001.

[8] Z. D. Cui, S. L. Wu, S. L. Zhu, and X. J. Yang, "Study on corrosion properties of pipelines in simulated produced water saturated with supercritical $\mathrm{CO}_{2}, "$ Applied Surface Science, vol. 252, pp. 2368-2374, 2006.

[9] A. Pfennig and A. Kranzmann, "Reliability of pipe steels with different amounts of $\mathrm{C}$ and $\mathrm{Cr}$ during onshore carbon dioxide injection," International Journal of Greenhouse Gas Control, vol. 5, pp. 757-769, 2011.

[10] H. Zhang, Y. L. Zhao, and Z. D. Jiang, "Effects of temperature on the corrosion behaviour of $13 \mathrm{Cr}$ martensitic stainless steel during exposure to CO2 and Cl- environment," Material Letters, no. 59, pp. 3370-3374, 2005.

[11] J. N. Alhajji and M. R. Reda, "The effect of alloying elements on the electrochemical corrosion of low residual carbon steels instagnant $\mathrm{CO}_{2}$-saturated brine," Corrosion Science, vol. 34, no. 11, pp. 1899-1911, 1993.

[12] Y.-S. Choi and S. Nešić, "Corrosion behaviour of carbon steel in supercritical CO2-water environments," in Proc. 2008 Conference and Expo, New Orleans, Louisiana, USA, March 16-20, 2008.

[13] X. Jiang, S. Nešić, and F. Huet, "The effect of electrode size on electrochemical noise measurements and the role of chloride on localized $\mathrm{CO}_{2}$ corrosion of mild steel," in Proc. NACE Corrosion 2008 Conference and Expo, New Orleans, Louisiana, USA, March 16-20, 2008.

[14] Z. Ahmad, I. M. Allam, and B. J. Abdul Aleem, "Effect of environmental factors on the atmospheric corrosion of mild steel in aggressive sea coastal environment," Anti Corrosion Methods and Materials, no. 47, pp. 215-225, 2000.

[15] P. Fennig and R. Bäßler, "Effect of $\mathrm{CO}_{2}$ on the stability of steels with $1 \%$ and $13 \% \mathrm{Cr}$ in saline water," Corrosion Science, vol. 51, issue 4, pp. 931-940, 2009.

[16] A. Pfennig and A. Kranzmann, "The role of pit corrosion in engineering the carbon storage site Ketzin, Germany," WIT Transactions on Ecology and the Environment, vol. 126, 2010, pp. 109-118.

[17] P. Zastrow, A. Kranzmann et al., "Influence of heat treatment on the corrosion behaviour of stainless steels during $\mathrm{CO}_{2}$-sequestration into saline aquifer," International Journal of Green House Gas Control, vol 15, pp. 213-224, 2003.

[18] R. Nyborg, "Controlling internal corrosion in oil and gas pipelines," Business Briefing: Exploration \& Production: The Oil \& Gas Review, issue 2, pp. 70-74, 2005.

[19] D. S. Carvalho, C. J. B. Joia, and O. R. Mattos, "Corrosion rate of iron and iron-chromium alloys in $\mathrm{CO}_{2}$-medium," Corrosion Science, no. 47 pp. 2974-2986, 2005.

[20] B. R. Linter and G. T. Burstein, "Reactions of pipeline steels in carbon dioxide solutions," Corrosion Science, no. 41, pp. 117-139, 1999.

[21] S. L. Wu, Z. D. Cui, G. X. Zhao, M. L. Yan, S. L. Zhu, and X. J. Yang, "EIS study of the surface film on the surface of carbon steel form supercritical carbon dioxide corrosion," Applied Surface Science, no. 228, pp. 17-25, 2004.

[22] Ș. Bülbül and Y Sun, "Corrosion behaviours of high Cr-Ni cast steels in the $\mathrm{HCl}$ solution," Journal of Alloys and Compounds, no. 598, pp. $143-147,2010$.

[23] B. Hou, Y. Li, Y. Li, and J. Zhang, "Effect of alloy elements on the anti-corrosion properties of low alloy steel," Bull. Mater. Sci, vol. 23, no. 3, pp. 189-192, 2000.

[24] Z. Cvijović and G. Radenković, "Microstructure and pitting corrosion resistance of annealed duplex stainless stell," Corrosion Science, vol. 48, pp. 3887-3906, 2006.

[25] J. Y. Park and Y. S. Park, "The effects of heat-treatment parameters on corrosion resistance and phase transformation of $14 \mathrm{Cr}-3 \mathrm{Mo}$ martensitic stainless steel," Materials Science and Engineering, pp. 449-451, pp. 1131-1134, 2007.

[26] J. Banaś, U. Lelek-Borkowska, B. Mazurkiewicz, and W. Solarski, "Effect of $\mathrm{CO}_{2}$ and $\mathrm{H}_{2} \mathrm{~S}$ on the composition and stability of passive film on iron alloy in geothermal water," Electrochimica Acta, vol. 52, pp. 5704-5714, 2007.

[27] P. D. Bilmes, C. L. Llorente, C. M. Méndez, and C. A. Gervasi, "Microstructure, heat treatment and pitting corrosion of $13 \mathrm{CrNiMo}$ plate and weld metals," Corrosion Science, vol. 51, issue 4, pp. 876-882, 2009

[28] L. Zhang, W. Zhang, Y. Jiang, B. Deng, D. Sun, and J. Li, "Influence of annealing treatment on the corrosion resistance of lean duplex stainless steel," 2101
[29] B. Brown, S. R. Parakala, and S. Nešić, " $\mathrm{CO}_{2}$ corrosion in the presence of trace amounts of H2S," Corrosion, Paper, no. 04736, pp. 1-28, 2004.

[30] A. N. Isfahany, H. Saghafian, and G. Borhani, "The effect of heat treatment on mechanical properties and corrosion behaviour of AISI420 martensitic stainless steel," Journal of Alloys and Compounds, no. 509, pp. 3931-3936, 2011.

[31] M. A. Lucio-Garciaa, J. G. Gonzalez-Rodrigueza, M. Casalesc, L. Martinezc, J. G. Chacon-Navaa, M. A. Neri-Floresa, and A. Martinez-Villafañea, "Effect of heat treatment on $\mathrm{H}_{2} \mathrm{~S}$ corrosion of a micro-alloyed C-Mn steel," Corrosion Science, vol. 51, pp. 2380-2386, 2009.

[32] C. Madduri and R. V. Prakash, "Corrosion Fatigue Crack Growth Studies in Ni-Cr-Mn steels," International Journal of Mechanical and Materials Engineering, vol. 1, pp. 20-25, 2010.

[33] M. Seo, "Electrochemical society. Corrosion division, passivity and localized corrosion: An international symposium in honour of professor Norio Sato, initiation and stability of localized corrosion processes on stein steels," The Electrochemical Society, pp. 483-490, 1999.

[34] V. Vignal, O. Delrue, J. Peultier, and R. Oltra, "Critical factors in localized corrosion 5: A symposium in honour of Hugh Isaacs, local mechanical-electrochemical behavior of duplex stainless steels," The Electrochemical Society, pp. 102-104, 2007.

[35] A. Pfennig, M. Wolf, and T. Böllinghaus, "Corrosion fatigue of X46Cr13 in CCS environment, in energy technology 2016: Carbon dioxide management and other technologies," vol. 1, pp. 49-56, 2016.

[36] A. Pfennig, R. Wiegand, M. Wolf, and C.-P. Bork, "Corrosion and corrosion fatigue of AISI $420 \mathrm{C}(\mathrm{X} 46 \mathrm{Cr} 13)$ at $60{ }^{\circ} \mathrm{C}$ in $\mathrm{CO}_{2}$-saturated artificial geothermal brine," Corrosion Science, vol. 68, pp. 134-143, 2013.

[37] J. Han, Y. Yang, S. Nešić, and B. N. Brown, "Roles of passivation and galvanic effects in localized $\mathrm{CO}_{2}$ corrosion of mild steel," in Proc. NACE Corrosion 2008, New Orleans, Louisiana, USA, March 2008

[38] A. Pfennig, H. Wolthusen, P. Zastrow, and A. Kranzmann, "Evaluation of heat treatment performance of potential pipe steels in CCS-environment," Carbon Dioxide Management and Other Technologies, vol. 1, pp. 15-22, 2015.

[39] A. Förster, B. Norden, K. Zinck-Jørgensen, P. Frykman, J. Kulenkampff, E. Spangenberg, J. Erzinger, M. Zimmer, J. Kopp, G. Borm, C. Juhlin, C. Cosma, and S. Hurter, "Baseline characterization of the CO2SINK geological storage site at Ketzin," Germany: Environmental Geosciences, vol. 13, no. 3, pp. 145-161, September 2006.

[40] M. Wolf, R. Afanasiev, T. Böllinghaus, and A. Pfennig, "Investigation of corrosion fatigue of duplex steel X2CrNiMoN22 53 exposed to a geothermal environment under different electrochemical conditions and load types," in Proc. 13th International Conference on Greenhouse Gas Control Technologies, pp. 14-18, November 2016 , Lausanne, Switzerland.

[41] A. Pfennig, K. Heynert, M. Wolf, and T. Böllinghaus, "First in-situ electrochemical measurement during fatigue testing of injection pipe steels to determine the reliability of a saline aquifer water CCS-site in the Northern German basin original," Energy Procedia, vol. 63, pp. 5773-5786, 2014.

[42] A. Pfennig, H. Wolthusen, and A. Kranzmann, "Unusual corrosion behavior of 1.4542 exposed a laboratory saline aquifer water CCS-environment," GHGT13, 2016, Lausanne, Switzerland.

[43] S. W. Kraus and G. Nolze, "Powder cell - A program for the representation and manipulation of crystal structures and calculation of the resulting X-ray powder patterns," J. Appl. Cryst., vol. 29, pp. 301-303, 1996.

[44] A. Pfennig, H. Wolthusen, M. Wolf, and A. Kranzmann, "Effect of heat treatment of injection pipe steels on the reliability of a saline aquifer water CCS-site in the Northern German basin," Energy Procedia, vol. 63, pp. 5762-5772, 2014

[45] A. Pfennig, M. Wolf, A. Gröber, T. Böllinghaus, and A. Kranzmann, "Corrosion fatigue of 1.4542 exposed to a laboratory saline aquifer water CCS-environment," GHGT13, November 2016, Lausanne, Switzerland.

[46] R. Cohen et al., "Low-cycle fatigue behaviour of 316L-type stainless steel in chloride solutions," Corrosion Science, vol. 51, pp. 3014-3120, 2009.

[47] A. Pfennig, R. Wiegand, M. Wolf, and C. P. Bork, "Corrosion and corrosion fatigue of AISI $420 \mathrm{C}(\mathrm{X} 46 \mathrm{Cr} 13)$ at $60{ }^{\circ} \mathrm{C}$ in $\mathrm{CO}_{2}$-saturated artificial geothermal brine," Corrosion Science, vol. 68, pp. 134-143, 2013. 
A. Pfennig was born in Büdelsdorf, Germany in April 1970. She studied minerology at the Rheinische Friedrich Wilhelms University Bonn, Germany, where she graduated in 1997. Her Ph.D. in the field of ceramic moulds for liquid metal casting was earned in 2001 from the Friedrich Alexander University of Erlangen, Germany. She then worked for Siemens Energy in charge of ceramic shields and transferred to Berlin in 2008 where she currently teaches material science for engineering students at the Applied University Berlin, HTW. A. Pfennig research interest and expertise is in the field of corrosion fatigue of materials at high temperature and high pressure simulating geothermal environments.

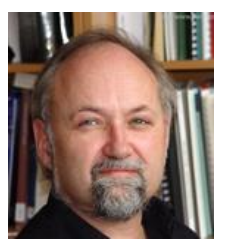

A. Kranzmann was born in Bad-Bibra, Germany in 1956. He studied physics at the University of Cologne, Germany and finished his Ph.D. 1988 in the field of metallurgy at the MPI for metals research, Germany, where he worked from 1986-1991. He then transferred to $\mathrm{ABB}$ AG in Heidelberg as head of section in charge of materials and surface technology and later R\&D coordination manager of ABB Germany until 2001. From then on and currently he is group leader "microstructure of materials" at the BAM, Federal Institute for Research and Development. A. Kranzmann research interest and expertise is in the field of high temperature and gas corrosion, ageing of metals, experimental simulation of high-temperature processes and research of surface topology. 